ISSN: 2277-3754

ISO 9001:2008 Certified

International Journal of Engineering and Innovative Technology (IJEIT)

Volume 11, Issue 1, July 2021

\title{
Conventional regeneration of spent activated carbon from brewer's spent grain
}

\author{
Ejikeme, Ebere M., Ejikeme, Patrick C.N., Nwosu, David C \\ Enugu State University of Science and Technology, Enugu, Nigeria.
}

\begin{abstract}
This work studied conventional regeneration of saturated activated carbon using muffle furnace. The activated carbon was prepared from brewer's spent grain using carbonization and chemical activation with potassium hydroxide. It was saturated with methylene blue dye and regenerated using muffle furnace. Effect of 30\% hydrogen peroxide $\left(\mathrm{H}_{2} \mathrm{O}_{2}\right)$ as an oxidant in the regeneration process was studied. Adsorption - regeneration process was studied for six cycles. Regeneration condition was optimized using central composite design (CCD). Effect of regeneration temperature and time on the adsorptive capacity of regenerated carbon was studied for one cycle. Adsorptive capacity and regeneration efficiency were found to decrease with increase in the number of cycles. $30 \% \mathrm{H}_{2} \mathrm{O}_{2}$ had a tremendous effect on the adsorptive capacity of the regenerated carbon. The adsorptive capacity increased as the temperature grew from $200^{\circ} \mathrm{C}$ to $500^{\circ} \mathrm{C}$, but dropped after being raised to $6,000^{\circ} \mathrm{C}$. Adsorptive capacity increased from 10 minutes to 30 minutes, but declined to 50 minutes. The Quadratic model was used to regenerate a long network of electronics devices. In this experiment, the parameters were exactly what were required for optimal adsorption: temperature of 537.76 degrees Celsius, time of 29.34 minutes, and an initial dye concentration of $100 \mathrm{mg} / \mathrm{L}$ with estimated adsorptive capacity of $54.2827 \mathrm{mg} / \mathrm{L}$. This was an extremely small mistake of 0.02 percent following validation.
\end{abstract}

Keywords: activated carbon, methylene blue dye, oxidant, regeneration, spent grain.

\section{INTRODUCTION}

The dye methylene blue is anionic in nature and largely utilised in textile industries. Dye in textile industries creates hazardous wastewater, which carries many harmful elements. A presence of methylene blue dye in water bodies decreases the rate of light absorption, which consequently inhibits photosynthesis. Dyes which concentrate above $1 \mathrm{mg} / \mathrm{l}$ in water are unsafe for human consumption and require treatment to ensure quality.

Filtration, chemical treatment, oxidation, and adsorption using activated carbon are the different procedures utilised for treating waste streams contaminated with dye. The activated carbon adsorption method is one of the most often utilised methods on the list.

In general, activated carbon is an amphoteric porous material, and it is commonly employed for adsorption of organic and inorganic chemicals. Carbon is typically obtained from various forms of coal, coconut shell, wood, or a chemical process in order to make activated carbon.

Manuscript received: 23 June 2021

Manuscript received in revised form: 21 July 2021

Manuscript accepted: 4 August 2021

Manuscript Available online: 15 August 2021
Although activated carbon has a long history, it is also the most used adsorbent to date. Activated carbon in waste water treatment has different characteristics depending on the area where it is present on the water and where it adsorbs the toxins. Activated carbon is great at adsorption, but because the available surface area and adsorption sites are limited, its potential effectiveness is limited.

Once the adsorption site is full, the activated carbon will no longer have adsorption capability, which means it has been wasted active carbon. If it is disposed of at a landfill, the carbon is regenerated and reused; if it is recycled, it is then reconstituted into its original chemical composition. In some cases, regenerating and reusing discarded activated carbon yields a great deal of financial profit [6]. Restoration of activated carbon's accessible surface area and adsorbate capacity happens through desorption and/or decomposition of saturated activated carbon [5].

The four main categories of carbon regeneration techniques are chemical, thermal, microbiological, and vacuum-based methods. Heating the wasted activated carbon to release or destroy adsorbate in the spent activated carbon is one type of thermal regeneration technologies, including steam, electro thermal swing adsorption, microwave regeneration, and gasification.

Thermal regeneration, which occurs most often, involves heating the adsorbed compounds to high temperatures and then watching for them to vaporise and oxidise.

Volatile chemicals are desorbed during heat regeneration, whereas less volatile compounds are degraded [9]. Spent activated has a high specific surface area and a large number of micro-pores. Regeneration of spent activated is therefore efficient. It was found that by treating spent activated carbons, their surface area increased over their untreated spent activated carbons.

$85 \%$ of the entire brewing industry by-products are accounted for using brewer's waste grain (BSG). Cellulose with around $17 \%$ cellulose, $28 \%$ non-cellose polysaccharides, including arabinoxylans, and $28 \%$ lignin is used to create the look of "battlestar" in this film.

The material described here was researched in depth to examine the traditional regeneration of activated carbon impregnated with methylene blue dye. Muffle furnace was the standard form of conventional regeneration.

\section{MATERIALS AND METHODS}

The adsorbate, molecular weight 319.9, empirical formula of C16H18N3SCL, was a mixture of methylene 
ISSN: 2277-3754

ISO 9001:2008 Certified

International Journal of Engineering and Innovative Technology (IJEIT)

Volume 11, Issue 1, July 2021

blue and glucose. This material was chosen for the study because of its previously reported high adsorption of compounds such as [13]. Figure 1 illustrates the chemical structure of methylene blue dye.<smiles>CN(C)c1ccc2nc3ccc(=[N+](C)C)cc-3sc2c1</smiles>

Fig 1: Chemical Structure of methylene blue dye.

Fresh brewer's spent grain was collected from Nigerian brewery ninth mile corner, Enugu, Enugu State. It was obtained immediately it was generated. It is the main byproduct of brewing industry and represents approximately $85 \%$ of total by product generated [14]. It contain about (70-80\%) moisture content [15].

\section{A. Production of activated carbon}

Pre-carbonization was carried out by using two steps: (1) pre-heating followed by (2) submersion in boiling water, and then (3) carbonization in a closed environment was accomplished using 6MPotassium hydroxide (KOH). To remove any contaminants from the surface, the spent grain was rinsed thoroughly with distilled water. The seeds were crushed and dried. This screen size was selected to produce meshes with a maximum size of 1-2 $\mathrm{mm}$. It was first dried out in a normal oven, and then put into a furnace where it was heated to 8,500 degrees Fahrenheit for one hour. To obtain an activated carbon that was both soluble and neutral, the resulting carbon was treated with multiple washes of 0.1-mM hydrochloric acid (HCL) and distilled water until neutral $\mathrm{pH}$ was attained.

\section{B. Saturation of Activated Carbon}

A solution of methylene blue dye concentration $100 \mathrm{mg} / \mathrm{l}$ to $400 \mathrm{mg} / \mathrm{l}$ was used to saturate the activated carbon. The dye-loaded activated carbon was steeped in the dye solution for a total of 24 hours to ensure that all of the dye-binding sites were saturated. After the activated carbon had been washed with distilled water, residual colouring was not absorbed, and the next step was rinsing the carbon with distilled water. The carbon was allowed to dry overnight before it was placed in the furnace. Equation 1 was utilised to discover the initial solid loading concentration of methylene blue on saturated $\left(\mathbf{q i} \frac{m g}{g}\right)^{\text {arbon. }}=\left(\frac{C_{o}-C_{e}}{m} \mathrm{~V}\right)$

Where qi is the initial solid phase dye concentration $(\mathrm{mg} / \mathrm{g}), \mathrm{Co}$ is the initial dye concentration used in saturation $(\mathrm{mg} / \mathrm{l}), \mathrm{Ce}$ is the equilibrium concentration of the dye after saturation $(\mathrm{mg} / \mathrm{l}), \mathrm{m}$ is the mass of the activated carbon $(\mathrm{g}), \mathrm{V}$ is the volume of dye solution used in saturation.

\section{Regeneration of saturated activated carbon}

Conventional regeneration means regenerating the saturated activated carbon thermally in a muffle furnace at $500^{\circ} \mathrm{C}$ for 30 minutes. Regeneration study was done for six cycles (adsorption-regeneration) with and without oxidant. 30\% hydrogen peroxide was used as an oxidant. Carbon could be regenerated using oxygen as follows: first, an amount of carbon $(0.02 \mathrm{~g})$ was immersed in $25 \mathrm{ml}$ of oxygen in a volume (calculated) for one hour at room temperature after which it was washed with distilled water and dried. to measure the sample's capacity to absorb components (2), while regeneration efficiency was calculated using equation (3).

$$
\begin{aligned}
& \text { qe } \quad=\quad \frac{C_{0}-C_{e}}{w} \mathrm{~V} \\
& R E(\%)= \\
& \frac{\text { Adsorption capacity of regenrated carbon }}{\text { Adsorptive capacity of fresh carbon }} \times 100
\end{aligned}
$$

Where:

qe $(\mathrm{mg} / \mathrm{g})$ is the amount of dye in the carbon at equilibrium, Ceis the initial dye solution $(\mathrm{mg} / \mathrm{l}), \mathrm{W}$ is the weight of the activated carbon $(\mathrm{g}), \mathrm{V}$ is the volume of dye solution (L), RE is the regeneration capacity(\%).

\section{Effect of Conventional Regeneration process factors}

On the adsorptive capacity of regenerated activated carbon For only one cycle, time and temperature effects on the adsorptive capacity of the regenerated carbon were tested. For regenerative health, the sample was first exposed to $30 \% \mathrm{H} 202$ solution for one hour at room temperature. A little sample of methylene blue dye was employed in the study. After regeneration, the regenerated carbon was subjected to adsorption for three hours, during which time the carbon underwent a complete regeneration. "Eq. [which] estimates the amount of carbon that can be absorbed by regenerated carbon" (2).

The effect of regeneration temperature was done by immersing the material in a bath of water at different temperatures for varying amounts of time, while the effect of regeneration time was done by immersing the material in a bath of water for varying lengths of time at $500^{\circ} \mathrm{C}$

\section{E. Optimization of conventional regeneration process}

Optimization of conventional regeneration process was done using response surface methodology (RSM). Approximation is employed to uncover real relationships between the dependent and independent variables in the initial step of RSM. The polynomial form of a mathematical model that predicts the response as a function of factors interacting with one another is constructed. While the behaviour of the system is primarily explained by the following quadratic equation, here's an alternative form: 
ISSN: 2277-3754

ISO 9001:2008 Certified

International Journal of Engineering and Innovative Technology (IJEIT)

Volume 11, Issue 1, July 2021

$$
\mathrm{Y}=\mathrm{bo}+\sum_{i=1}^{n} b i x i+\sum_{i=1}^{n} b i i x^{2} i i+b i j x i x j
$$

A Response predicted by $\mathrm{Y}$ is plotted on the $\mathrm{X}$-axis. Bo, the offset term, represents the estimated response. $\mathrm{Bi}$, the linear effect, represents the estimated response. Bii, the squared effect, represents the estimated response. Finally, the effect of coded independent variables $x i$ and $x j$ are plotted on the $\mathrm{x}$-axis.

Central composite design (CCD) was used for the conventional regeneration conditions. It involves three numeric factors of temperature; time and initial dye concentration used for the saturation. The response was the adsorptive capacity of the regenerated carbon.

The regeneration study was done for only one cycle without an oxidant. The extent of the regeneration was evaluated by carrying out adsorption process with the regenerated carbon using 50mglL of methylene blue dye solution. The adsorption capacity after regeneration was calculated and used as the response. Factors and levels used for the optimization process is shown on table 1 .

Table 1: Factors and levels used for the optimization

\begin{tabular}{|ll|l|l|l|l|l|l|}
\multicolumn{10}{c|}{ process. } \\
\hline \multicolumn{2}{|c|}{ Factors } & & & & \multicolumn{3}{|c|}{ Levels } \\
\hline & & Unit & $-\propto$ & -1 & 0 & +1 & $+\infty$ \\
\hline 1 & $\begin{array}{l}\text { Temperatu } \\
\text { re }\end{array}$ & OC & $\begin{array}{l}200 . \\
0\end{array}$ & $\begin{array}{l}300 . \\
0\end{array}$ & $\begin{array}{l}400 . \\
0\end{array}$ & $\begin{array}{l}500 . \\
0\end{array}$ & $\begin{array}{l}600 . \\
0\end{array}$ \\
\hline 2 & Time & Minut & 20.0 & 30.0 & 40.0 & 50.0 & 60.0 \\
. & es & & & & & \\
\hline 3 & $\begin{array}{l}\text { Initial dye } \\
\text { concentrati } \\
\text { on }\end{array}$ & mg/l & 50.0 & $\begin{array}{l}100 . \\
0\end{array}$ & $\begin{array}{l}150 . \\
0\end{array}$ & $\begin{array}{l}200 . \\
0\end{array}$ & $\begin{array}{l}250 . \\
0\end{array}$ \\
\hline
\end{tabular}

\section{RESULTS}

\section{A. Characterization of activated carbon}

Before and after typical regeneration, the activated carbon generated was characterised. After six regeneration cycles, the dye concentration was raised to $100 \mathrm{mg} / \mathrm{L}$ for saturation and adsorption, and characterisation was completed. In this table, we show the effects of regeneration on the characteristics of the activated carbon. This can be attributed to attrition, collapse of carbon matrix and conversion of micro pore to larger pore sizes. The iodine number of regenerated carbon also dropped. According to Mustafa et al., [18] micropore capacity can be expressed as the iodine number. It is assumed that iodine can penetrate into micropore while methylene blue dye cannot. The regenerated carbon recorded low iodine number because of reduction of micropore volume.

Table 2: Properties of fresh and regenerated activated carbons

\begin{tabular}{|cl|l|l|l|}
\hline & Parameters & \multicolumn{1}{|c|}{ Units } & $\begin{array}{c}\text { Fresh } \\
\text { activated } \\
\text { carbon }\end{array}$ & $\begin{array}{c}\text { Conventional } \\
\text { regenerated } \\
\text { carbon }\end{array}$ \\
\hline 1 & Surface area & $\mathrm{m}^{2} / \mathrm{g}$ & 556.0 & 450.2 \\
\hline 2 & Iodine number & $\mathrm{mg}_{2}{ }_{2} / \mathrm{g}$ & 1068.0 & 708.3 \\
\hline
\end{tabular}

\begin{tabular}{|ll|l|l|l|}
\hline 3 & $\begin{array}{l}\text { Moisture } \\
\text { contact }\end{array}$ & $\%$ & 3.5 & 3.3 \\
\hline 4 & Ash Content & $\%$ & 3.4 & 6.2 \\
\hline 5 & $\begin{array}{l}\text { Volatile } \\
\text { matter }\end{array}$ & $\%$ & 3.8 & 2.6 \\
\hline 6 & Fixed carbon & $\%$ & 89.3 & 87.9 \\
\hline 7 & $\mathrm{P}_{\text {P2C }}^{\mathrm{H}}$ & - & 6.2 & 8.3 \\
\hline 8 & $\mathrm{P}^{\mathrm{H}}$ & - & 6.5 & 7.0 \\
\hline 9 & Bulk density & $\mathrm{g} / \mathrm{ml}$ & 0.49 & 0.46 \\
\hline
\end{tabular}

Figure 1(a-c) show the SEM analysis of un-activated, activated and conventional regenerated activated carbons. The surface of the activated carbon shows distinct pores compared to the un-activated one. The surface of conventional regenerated carbon shows larger pores compared to the activated one. This is probably due to the conversion of micro pores to meso pores as a result of thermal treatment. Small grains were seen inside the pores of regenerated carbon. This shows that conventional regeneration did not completely remove the adsorbed methylene blue dye.
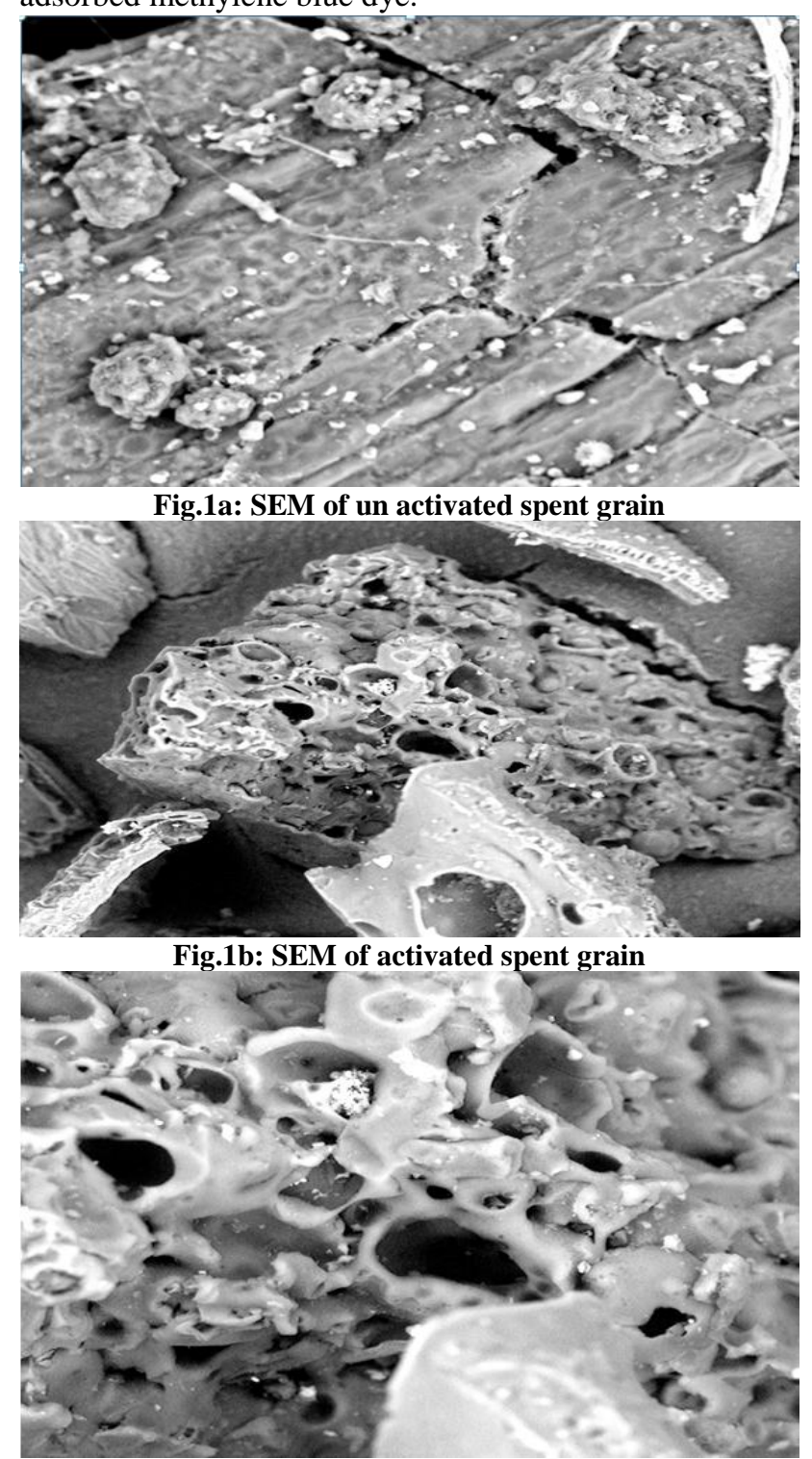

Fig.1c: SEM of Conventionally regenerated carbon 
ISSN: 2277-3754

\section{ISO 9001:2008 Certified \\ International Journal of Engineering and Innovative Technology (IJEIT) \\ Volume 11, Issue 1, July 2021}

Figures 2 (a-d) shows the FTIR of the un-activated, activated, saturated and regenerated carbons. FTIR spectrum of the activated carbon indicated presence of fewer functional groups compared to the un-activated one. This shows that the surface functional groups of the raw samples absolutely disappeared in the activated carbon spectrum while those remaining were weak to a great extent. Spectrum of the saturated carbon showed many functional groups compared to the activated carbon. This can be attributed to the dye adsorbed on the activated carbon. The spectrum of the regenerated carbon has fewer functional groups compared to saturated carbon. This was as a result of desorption of the adsorbed dye which in turn reduced the functional groups present. It can equally be observed that the functional groups in the regenerated carbon were close to the fresh activated carbon.
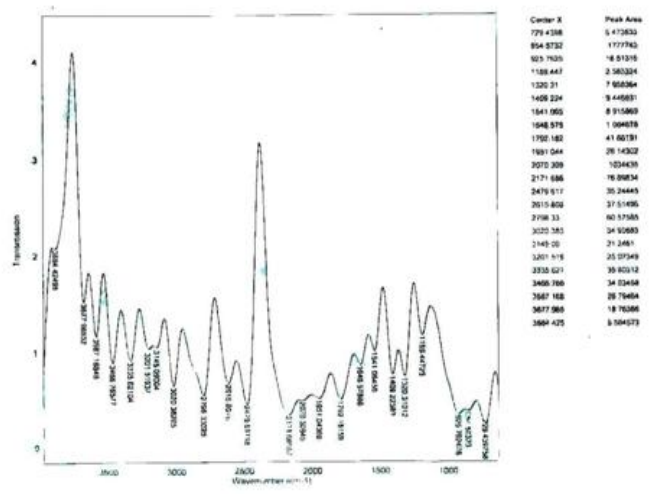

Fig. 2a: FTIR of inactivated spent grain

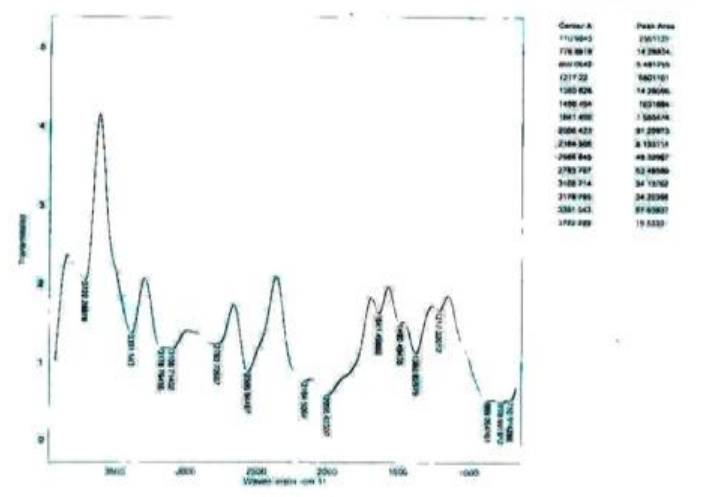

Fig.2b: FTIR of activated carbon

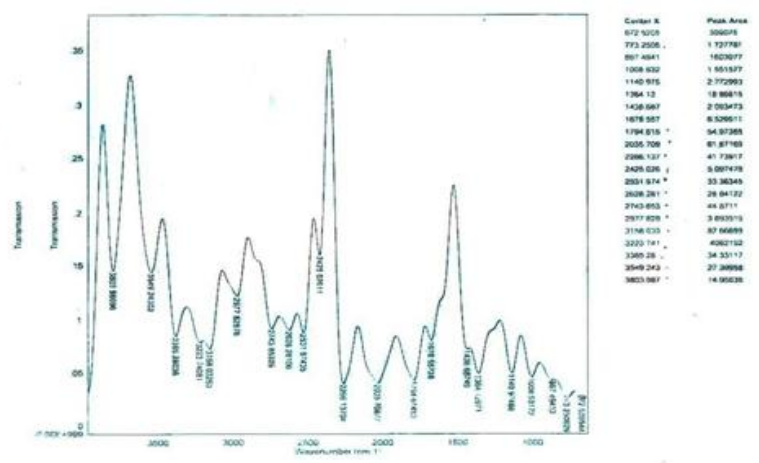

Fig. 2c: FTIR of saturated carbon

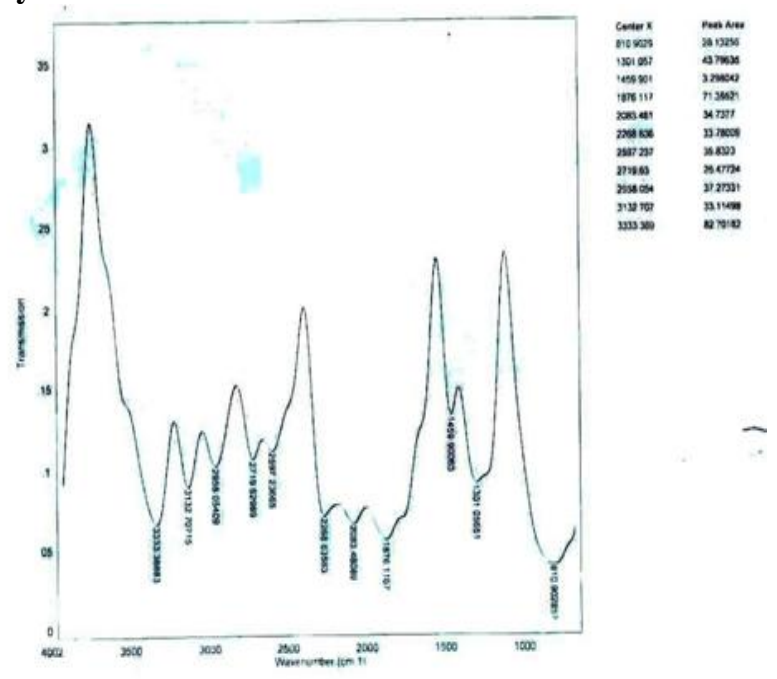

Fig. 2d: FTIR of conventionally regenerated carbon

\section{B. Effect of initial dye concentration on the saturation of activated carbon.}

Table 3 shows the result of initial dye concentration used for saturation on the initial solid phase concentration of the active carbon.

It was observed that increase in initial dye concentration led to increase in initial solid phase concentration. This can be attributed to increase in mass transfer driving force as the initial solid concentration was increased [19].

Table 3: Initial solid phase concentration

\begin{tabular}{|l|l|}
\hline $\begin{array}{l}\text { Initial dye concentration } \\
(\mathrm{mg} / \mathrm{l})\end{array}$ & $\begin{array}{l}\text { Initial solid phase } \\
\text { concentration }(\mathrm{mg} / \mathrm{g})\end{array}$ \\
\hline 100.00 & 124.36 \\
\hline 200.00 & 248.85 \\
\hline 300.00 & 347.27 \\
\hline 400.00 & 441.49 \\
\hline
\end{tabular}

\section{Regeneration cycle of saturated carbon}

Figure 3 and 4 show the adsorption capacity and regeneration efficiency of the regenerated carbon for six cycles.

It was observed that adsorptive capacities of the regenerated carbon increased with increased in initial dye concentration. This suggested that conventional regeneration was effective in freeing the pores of the activated carbon for successive adsorption.

Regeneration efficiency was observed to decrease as initial dye concentration was increased. The decrease can be attributed to inefficient desorption recorded at higher initial solid phase concentration. Regeneration efficiency was equally observed to decrease with successive cycles of adsorption - regeneration. This can be attributed to the shrinkage of pores of the carbon surface resulting to decrease in total surface area thereby reducing the accessible surface for methylene blue dye binding. This was in agreement with the work done by Mohammed in the adsorption of B-carotene. 
ISSN: 2277-3754

ISO 9001:2008 Certified

International Journal of Engineering and Innovative Technology (IJEIT)

Volume 11, Issue 1, July 2021

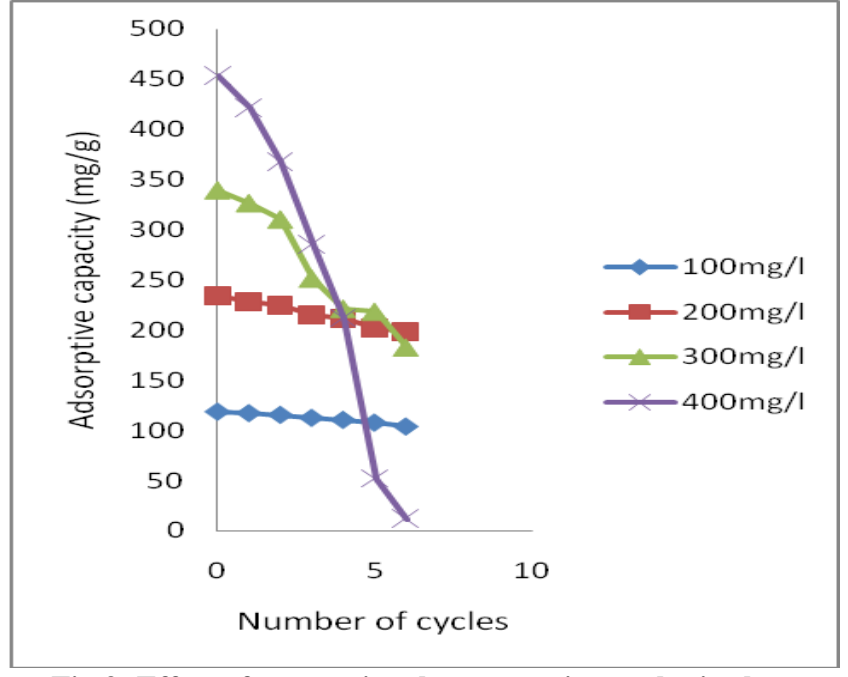

Fig 3: Effect of conventional regeneration cycles in the adsorptive capacity of saturated activated carbon.

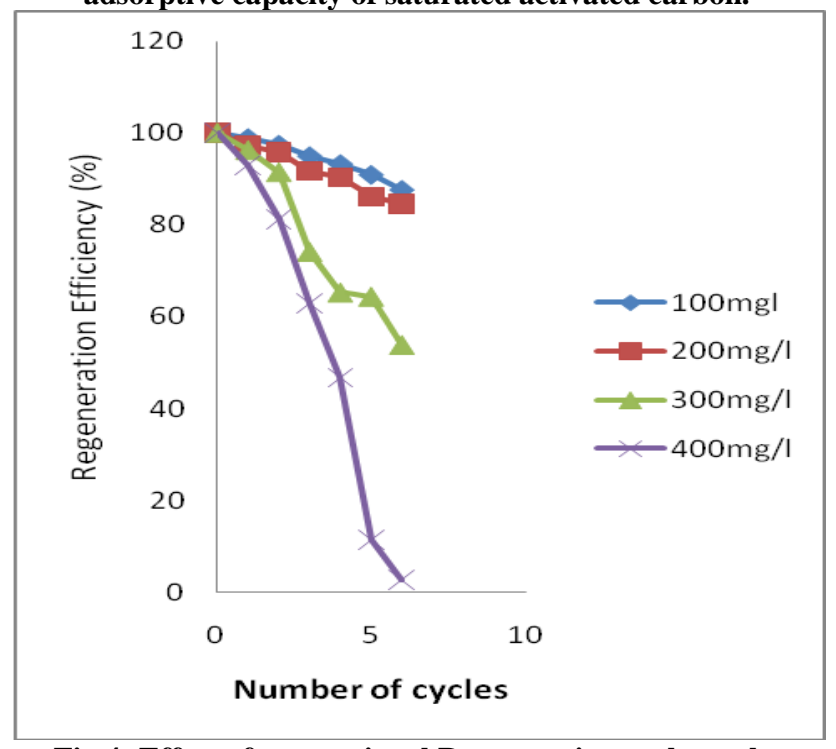

Fig 4: Effect of conventional Regeneration cycle on the regeneration efficiency of saturated activated carbon.

D. Effect of conventional regeneration temperature on the adsorptive capacity of regenerated carbon.

The solution was saturated with $100 \mathrm{mg} / \mathrm{L}$ of activated carbon. Fresh activated carbon was shown with a point zero symbols. The graph in Figure 5 illustrates the adsorptive capacity of regenerated carbon depending on the temperature. Regenerated carbon showed a lower adsorptive ability than fresh carbon. Higher adsorptive capacity was seen as adsorption rose from 2000C to 5000C, and beyond that the adsorptive capacity decreased. When desorbed, Methylene blue dye was soluble in water between $200-500$ oC. The heat grew, and the adsorbate volatilized, with the temperature rising to 500OC. Adsorptive capacity at a higher temperature is blocked by degraded carbonaceous residue, causing a drop in adsorptive capacity.

Conventional heating typically utilises an outside source of heat for the carbon bed, which is then heated by direct and indirect heat transfer. This creates a temperature gradient from the surface to the centre of the material, resulting in lower furnace temperatures. Secondary reactions occur where the second highest temperature is found, which is found towards the outer surface of the material.

These secondary reactions results in decomposition of the volatiles and larger amount of amorphous carbon being deposited in the porous structure of activated carbon .

The lower adsorptive capacity obtained for the regenerated carbon compared to the fresh one shows that conventional regeneration studied under the specified conditions cannot restore completely the pore sites of the carbon.

There was a sharp and distant difference between the adsorptive capacities of the saturated carbon regenerated with and without oxidant at lower temperature but the difference was minimal at higher temperature. At lower temperatures, the oxidant succeeded in removing any carbonaceous residue blocking the pores with resultant increase in adsorptive capacity. At higher temperatures, the oxidant was unable to remove appreciable amount of the decomposed residue because of the non oxidizing atmosphere used. Pyrolysis should not be undertaken in an atmosphere with no oxygen to avoid forming graphitized residue, which is the same as activated carbon. In this way, further selective oxidation is more difficult since the structure of the activated carbon will be damaged. It may be concluded that at high temperatures, the adsorptive capabilities of the carbons approximately equal in response to both oxidants and free radicals.

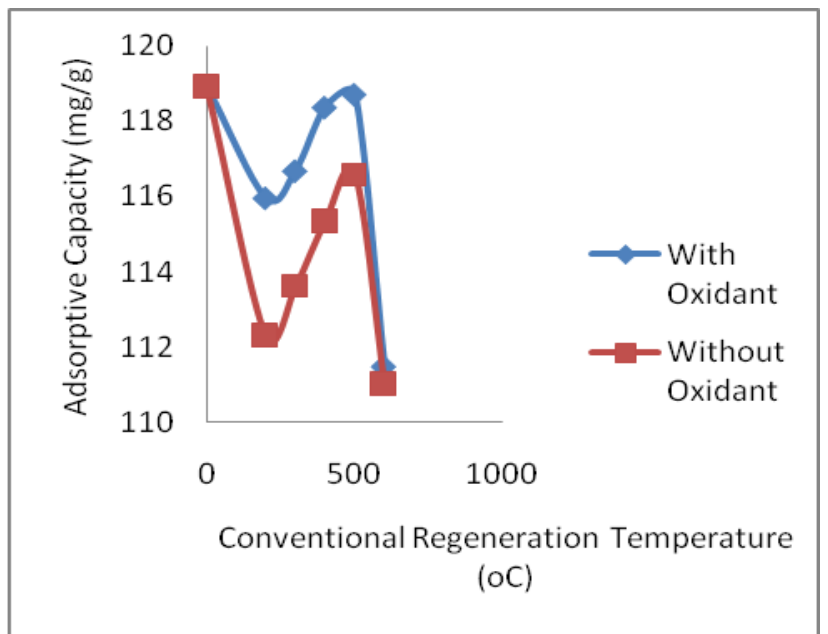

Fig.5: Effect of conventional regeneration temperature in the adsorptive capacity of regenerated activated carbon.

E. Effect of conventional regeneration time in the adsorptive capacity of regenerated carbon.

Effect of regeneration time was studied at temperature of $500^{\circ} \mathrm{C}$. Figure 6 shows the effect of regeneration time on the adsorptive capacity of regenerated carbon. It was observed that adsorptive capacity dropped at time of $10 \mathrm{mins}$ and subsequently increased as times was increased to $30 \mathrm{mins}$. It was observed to decrease beyond 
ISSN: 2277-3754

\section{ISO 9001:2008 Certified}

\section{International Journal of Engineering and Innovative Technology (IJEIT)}

Volume 11, Issue 1, July 2021

time of $30 \mathrm{mins}$, time of $10 \mathrm{mins}$ was not sufficient to initiate desorption.

The micro pores converted practically stoichiometrically into meso pores, while the macro pores were unaffected. Because to erosion of the matrix between the micro holes, there was a modest increase in adsorptive capacity. Micro pores are thought to be unreceptive to larger molecules such as methylene blue; hence meso pores are generally calculated as a methylene blue number.

This means that because the erosion of micro holes increased the surface area available for adsorption, the increased absorption of methylene blue dyes occurred. After 30 minutes, adsorptive capacity had decreased. While the approximate time frame for conversion from micro pores to bigger pore types varies with the time interval, progressive breakdown of the activated carbon matrix allows for the progression from small pores to larger ones. To summarise, this study has proven to increase mesopore and macropore volume and decrease micropore volume. Fresh carbon adsorptive capacity was found to be lower than that of regeneration activated carbon. Regeneration rates have been shown to be ineffective using standard methods. Additionally, the regenerative process was found to have a greater adsorptive capability using oxidant.

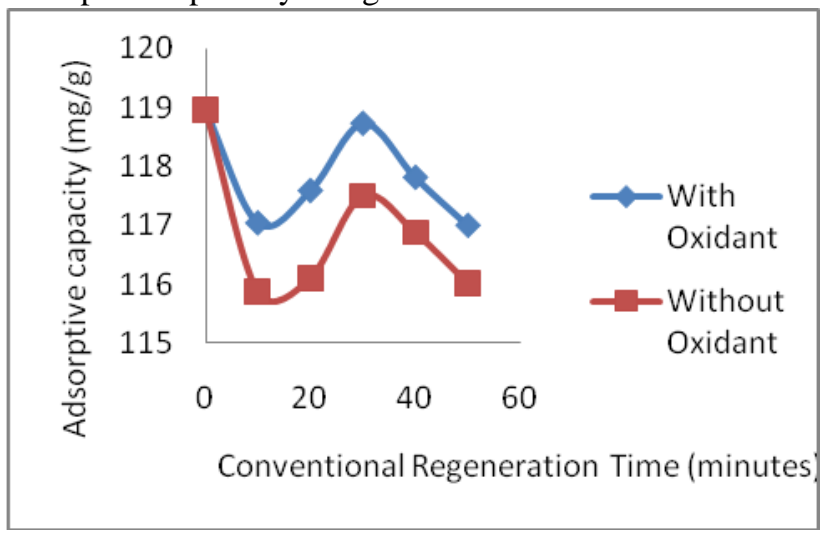

Fig.6: Effect of Conventional regeneration time on the adsorptive capacity of regenerated carbon.

\section{F. Optimization of conventional regeneration process}

As a part of a regeneration process, a central composite design was utilised to maximise conventional regeneration process variables (CCD). In Figure 3, you can see the analysis of variance on the table. The model $\mathrm{F}$ value of 22.71, together with other testing results, showed that the model was significant. The possibility of a $0.01 \%$ "Model F-value" being generated by random noise is almost 0 . If the value of the prob $>F$ (probability of falsification) is less than 0.05 , the model terms are statistically significant.

Temperature, beginning dye concentration, and time all had linear and quadratic influences on the outcome, although temperature had the strongest linear effect and time had the strongest quadratic effect. If the model terms were insignificant, then values greater than 0.1 were present.
When a fit F-value of 1.73 is used, which reflects pure error; it suggests that there is no substantial lack of fit. A $28.38 \%$ likelihood that this "lack of fit F-Value" is due to noise was present.

The projected R-squared of 0.7325 was somewhat lower than the Adjusted R-squared of 0.8727 , but that is to be expected, given the nature of the model. An appropriate signal was given by an accuracy of 18.394 .

Table 3: ANOVA table for conventional Regeneration process.

\begin{tabular}{|l|l|l|l|l|l|}
\hline Source & $\begin{array}{l}\text { Sum of } \\
\text { squares }\end{array}$ & df & $\begin{array}{l}\text { Mean } \\
\text { square }\end{array}$ & F value & $\begin{array}{l}\text { P-value } \\
\text { Prob>F }\end{array}$ \\
\hline Model & 424.75 & 6 & 70.79 & 22.71 & $<0.0001$ \\
\hline $\begin{array}{l}\text { A } \\
\text { Temperature }\end{array}$ & 94.47 & 1 & 94.47 & 30.31 & 0.0001 \\
\hline $\begin{array}{l}\text { B - Initial dye } \\
\text { concentration }\end{array}$ & 42.38 & 1 & 42.38 & 13.60 & 0.0027 \\
\hline $\begin{array}{l}\text { C - Time } \\
\text { A }\end{array}$ & 166.75 & 1 & 166.75 & 53.50 & $<0.0001$ \\
\hline $\mathrm{A}^{2}$ & 28.45 & 1 & 28.45 & 9.13 & 0.0098 \\
\hline $\mathrm{B}^{2}$ & 43.22 & 1 & 43.22 & 13.87 & 0.0026 \\
\hline $\mathrm{C}^{2}$ & 40.52 & 13 & 3.12 & & \\
\hline Residual & 29.75 & 8 & 3.72 & 1.73 & 0.2838 \\
\hline Lack of Fit & 10.77 & 5 & 2.15 & \multicolumn{2}{|l|}{} \\
\hline Pure Error & 465.26 & 19 & & & \\
\hline Cor Total & & & & & \\
\hline
\end{tabular}

Equation 4 and 5 show the model equation for the conventional regeneration process for both coded and actual factors respectfully.

Adsorptive capacity $(\mathrm{mg} / \mathrm{g})=+48.35+2.43 \mathrm{~A}-1.63 \mathrm{~B}+$ $3.23 \mathrm{C}-1.10 \mathrm{~A}^{2}+1.066^{2}-1.31 \mathrm{C}^{2}$

Adsorptive capacity $(\mathrm{mg} / \mathrm{g})=+17.92200+0.12318$ conventional temperature $\left({ }^{\mathrm{O}} \mathrm{C}\right)-0.16020$ initial dye concentration $(\mathrm{mg} / \mathrm{l})+0.84727$ conventional time (mins) - 10.09873E-004 conventional temperature $\left({ }^{0} \mathrm{C}\right)^{2}+$ $4.25510 \mathrm{E}-004$ initial dye concentration $(\mathrm{mg} / \mathrm{l})^{2}-$ 0013111 conventional time (mins) ${ }^{2}$

Table 4 shows the actual value, values predicted by the model and the residuals according to standard order. The normal plot of residual (fig 7) showed that the residuals followed normal distribution. Fig 8 shows the plot of predicted versus actual factors which indicated whether there is a value or group of values that were not easily predicted by the model. The two plots showed that the model equation generated can be used to predict the response.

Table 4: Residuals from the model

\begin{tabular}{|c|c|c|c|}
\hline $\begin{array}{c}\text { Standard } \\
\text { order }\end{array}$ & $\begin{array}{c}\text { Actual } \\
\text { values }\end{array}$ & $\begin{array}{c}\text { Predicted } \\
\text { values }\end{array}$ & Residuals \\
\hline 1 & 40.90 & 42.97 & -2.07 \\
\hline 2 & 45.34 & 47.83 & -2.49 \\
\hline 3 & 39.90 & 39.72 & 0.18 \\
\hline 4 & 45.05 & 44.58 & 0.47 \\
\hline
\end{tabular}


ISSN: 2277-3754

ISO 9001:2008 Certified

International Journal of Engineering and Innovative Technology (IJEIT)

Volume 11, Issue 1, July 2021

\begin{tabular}{|c|c|c|c|}
\hline 5 & 49.18 & 49.93 & -0.25 \\
\hline 6 & 57.00 & 54.29 & 2.71 \\
\hline 7 & 47.86 & 46.18 & 1.68 \\
\hline 8 & 49.73 & 51.03 & -1.30 \\
\hline 9 & 39.19 & 39.10 & 0.094 \\
\hline 10 & 48.99 & 48.82 & 0.17 \\
\hline 11 & 56.78 & 55.56 & 0.92 \\
\hline 12 & 48.70 & 49.35 & -0.65 \\
\hline 13 & 38.47 & 36.65 & 1.82 \\
\hline 14 & 48.01 & 49.56 & -1.55 \\
\hline 15 & 47.83 & 48.35 & -0.52 \\
\hline 16 & 45.95 & 48.35 & -2.40 \\
\hline 17 & 49.35 & 48.35 & 1.00 \\
\hline 18 & 49.40 & 48.35 & 1.05 \\
\hline 19 & 49.92 & 48.35 & 1.57 \\
\hline 20 & 47.92 & 48.35 & -0.43 \\
\hline
\end{tabular}

Table 5. Validation of Optimum conditions

\begin{tabular}{|c|c|c|c|c|c|}
\hline \multirow[t]{2}{*}{$\begin{array}{l}\text { Temperat } \\
\text { ure }\left({ }^{\circ} \mathrm{C}\right)\end{array}$} & \multirow{2}{*}{$\begin{array}{l}\text { Initial dye } \\
\text { concentrat } \\
\text { ion }\end{array}$} & \multirow{2}{*}{$\begin{array}{l}\text { Time } \\
(\mathrm{min} \\
\mathrm{s})\end{array}$} & \multicolumn{2}{|c|}{$\begin{array}{l}\text { Adsorptive Capacity } \\
(\mathrm{mg} / \mathrm{l})\end{array}$} & \multirow[t]{2}{*}{$\begin{array}{l}\text { Err } \\
\text { or }\end{array}$} \\
\hline & & & $\begin{array}{c}\text { Predict } \\
\text { ed } \\
\text { value }\end{array}$ & $\begin{array}{l}\text { Experimen } \\
\text { tal value }\end{array}$ & \\
\hline 550.00 & 100.00 & $\begin{array}{l}30.0 \\
0\end{array}$ & $\begin{array}{l}54.289 \\
9\end{array}$ & 54.300 & $\begin{array}{l}0.0 \\
2\end{array}$ \\
\hline
\end{tabular}

\section{CONCLUSION}

This study demonstrated that activated carbon can be produced from breweries spent grain. It was equally observed that conventional method using muffle furnace can regenerate saturated activated carbon. 30\% Hydrogen peroxide can be used as an oxidant in freeing the adsorbed dyes on the pore of the activated carbon. The saturated activated carbon can be regenerated using these optimum conditions; temperature of $537.76^{\circ} \mathrm{C}$, time of 29.34minutes, and saturation concentrations of $54.2827 \mathrm{mg} / \mathrm{g}$.

\section{ACKNOWLEDGMENT}

The authors wish to acknowledge TERTIARY EDUCATION TRUST FUND (TETFUND) for sponsoring this research work.

\section{REFERENCES}

[1] C. C. Nikita, M. Srinivas Kini, "A review in adsorption of cationic dyes using activated carbon", International Conference on Research in Mechanical Engineering Sciences, MATEC Web of conferences, 144, 02022, 2018,pp:1-16.

[2] S. Karaca., A. Gurses, M. Acikyildiz, M. Ejder, "Adsorption of cationic dye from aqueous solutions by activated carbon Microporos", Mesoporous mater 115, 2008, pp: $376-382$.

[3] Mohammed Amran Mohd Salleh, Dalia Khalid Mahmood, Wanazlina Wan Abdulkarim, Azniidris, "Cationic and anionic dye adsorption by agricultural solid wastes: a comprehensive review, Desalination, Volume 280, Issues 1-3, 3 October 2011, pp: 1-13.

[4] M. N. Nasruddin, Muhammed, Ridwan Fahmi, Chezulzikram, Azner Abdini, TanSze Yen, "Regeneration of spent activated carbon from waste water treatment plant Application", SEMIRATA - International Conference on Science and Technology, Journal of physics. Conf. serce 1116, 0320zz, 2018, pp: 1-9.

[5] Kang Sun, Jian-Chun Jiang, Jun-Ming Xu, "Chemical regeneration of exhausted Granular activated carbon used in Citric Acid fermentation solution decoloration", Iran. J. Chem. Chem. Eng, Vol. 28, No. 4, 2009, pp: 79-83.

[6] R. J. Martin., W. J. Ng., "Chemical regeneration of exhausted Activated carbon - 1", water Res. 18, 59, 1984,pp:1-6.

[7] N. Moona K. R. Murphy, M. Bondelind, O. Bergstedt, T. J. R. Peterson, "Partial renewal of granular activated carbon 
ISSN: 2277-3754

ISO 9001:2008 Certified

International Journal of Engineering and Innovative Technology (IJEIT)

Volume 11, Issue 1, July 2021

biofilter for improved drinking water treatment", Environ. Sci. water Res. Technol. 4, 2018 pp: 529 - 538.

[8] A. Bagreev. H. Rahmen, T. J. Bandosz, "Thermal regeneration of a spent activated carbon previously used as hydrogen sulfide adsorbent carbon", N.Y, 39, 2007, pp: $1319-1326$.

[9] Jung Eun Park, GiBbum Lee, Bum U Hong, Sang Youp Hwang, "Regeneration of activated carbons spent by waste water treatment using $\mathrm{KOH}$ chemical Activation”, Applied Science 9, 5132, 2019, pp:1-10.

[10] S. I. Mussalto, G. Dragone, I. C. Roberto, "Brewer's spent grain: generation, characteristics and potential applications", Journal of cereal science, vol 43, 2006, pp: 1 -14 .

[11] Kuang Yu, Xiaoping Zhang, Shaoqi Zhou, "Absorption of methylene blue in water onto activated carbon by surfactant modification”, water, 12(2), 587, 2020, pp:1-19.

[12] R. Kosseva Marie, "Sources, characteristics and treatment of plant based food waste", Food industry waste second edition, Assessment and Recuperation of Commodities 2020, pp: 37-66.

[13] Mateusz Jackowski, Lukasz Niedzwiecki, Kacper Jagiello, Oliwia Uchenska, Anna Trusek, "Brewer spent grains valuable Beer industry by product", Bio molecules, 10, 1669, 2020, pp:1-18.

[14] Kalu Samuel Ukanwa, Kumar Patchigolls, Ruben sakrabani, Edward Anthony, Sachin Mendavgane, "A review of chemicals to produce activated carbon from agricultural waste biomass", Sustainability, 11(22), 6204, 2019, pp:1-15.

[15] Mustafa Kaya, Omer sahim, CaferSaka, "Preparation and TG/DFG, FT - IR, SEM, BET surface Area, Iodine number and Methylene blue number analysis of activated carbon from pistachio shells by chemical activation", International journal of chemical reactor Engineering Vol 16, Issue 2, 2017, pp:1-29.

[16] Abolghasemi Hossein, Moosavian Mohammad Ali; Radpoursaeid Reza, "Effect of a surfactant concentration in the mass transfer in a mixer - settler extractor", Iran .J. Chem. Eng 25, 4, 2006, pp:9-15.

[17] Muhammad, Moonis, A.K, Thomas, S.Y.C., Chuah, T.G, Robiah, Y., Taufigi, Y.H., "Desorption of B-Carotene from mesoporous carbon monlith isotherm, kinetics and regeneration studies", Chemical Engineering Journal, 173, 2011, pp: $474-479$.

[18] Simon Shackley, Greet Ruysschaert, kor z wart, "Bruno Glaser Routledge Biochar in European soils and agriculture", Science and practice Mo, 2016, pp: $222-$ 224.

[19] Y. Fernandez, A. Arenillas, J. A. Menendez, "Microwave heating applied to pyrolysis, in Grundes, S. (Ed.)", Advances in induction and microwave heating of mineral and organic materials, 2011, pp:723-751.

\section{AUTHOR BIOGRAPHY}

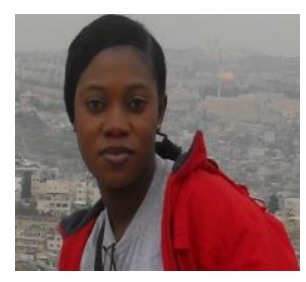

Engr. Dr. (Mrs) Ejikeme, Ebere .M. is a lecturer in the Department of Chemical Engineering, Enugu State University of Science and Technology Enugu Nigeria .She is a member of Council for Regulation of Engineering Practice in Nigeria, (COREN), Nigerian Society of Chemical Engineers and Nigerian Society of Engineers. She has a lot of publications and has authored so many books.

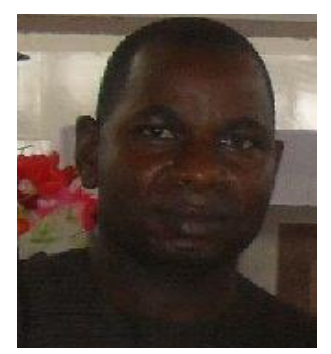

Engr. Dr.Ejikeme, P. C. N. is an associate professor of Chemical Engineering in the Enugu State University of Science and Technology Enugu Nigeria. $\mathrm{He}$ is a member of Council for Regulation of Engineering Practice in Nigeria, (COREN), Nigerian Society of Chemical Engineers and Nigerian Society of Engineers. He has a lot of publications and has authored so many books.

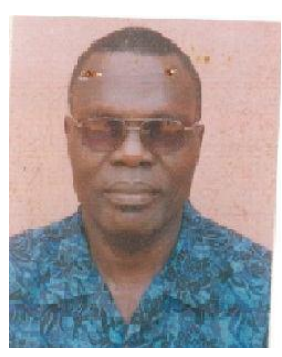

Engr. Dr. Nwosu, David C. is a lecturer in Chemical Engineering Department of Enugu State University of Science and Technology, Enugu. He is a member of Council for Regulation of Engineering Practice in Nigeria, (COREN), Nigerian Society of Chemical Engineers and Nigerian Society of Engineers. He has a lot of publications and has authored so many books 